\title{
Aspectos da política educacional para apenados no Rio Grande do Norte
}

\author{
Camila Virgínia Gomes Pessoa ${ }^{1}$ \\ Alcides Leão Santos Júnior ${ }^{2}$
}

\begin{abstract}
Resumo
O objetivo deste estudo é analisar como ocorrem as políticas públicas de alfabetização e ensino formal desenvolvidas em prol dos condenados à pena privativa de liberdade que cumprem essa pena nos regimes fechado e semiaberto em estabelecimentos prisionais no Estado do Rio Grande do Norte, narrando e discutindo os seus principais aspectos e objetivos. Inicialmente, são apresentadas estatísticas atualizadas sobre o sistema prisional brasileiro e norte-rio-grandense e, também, dados relevantes sobre o perfil socioeconômico dos apenados do Estado. A captura desses dados foi realizada por meio de revisão bibliográfica da literatura científica, especialmente artigos científicos, além de documentos e resoluções do Ministério da Educação e da Secretaria Estadual de Educação e Cultura do RN. Foi analisada também a legislação vigente, que garante a educação como direito fundamental, com enfoque na Constituição Federal Brasileira de 1988, Lei Federal no 9.394 (Lei de Diretrizes e Bases da Educação Nacional) e Lei Federal no 7.210/1984 (Lei de Execução Penal), e, por fim, as estatísticas oficiais do Conselho Nacional de Justiça atinentes ao Sistema Penitenciário. O trabalho ainda discute a disponibilização de políticas públicas de educação no contexto prisional, respeitando os direitos humanos, ao mesmo tempo em que procura desenvolver um conjunto de competências e preparar o indivíduo para a (re)inserção social, no papel de cidadão consciente de seus direitos e deveres.
\end{abstract}

Palavras-chave: Sistema prisional. Educação. Rio Grande do Norte.

\begin{abstract}
The objective of this study is to analyze how the public policies of literacy and formal education are developed for those sentenced to deprivation of liberty who serve their sentence in total or partial incarceration in prisons in the State of Rio Grande do Norte, narrating and discussing about the main aspects and objectives. Initially, updated statistics on the Brazilian and Rio Grande do Norte's prison system are presented, as well as relevant data on the socioeconomic profile of the prisoners. Data was collected through a literature review of the scientific texts, especially scientific articles, as well as documents and resolutions of the Ministry of Education and the State Department of Education and Culture of Rio Grande do Norte. It was also analyzed the current legislation that guarantees education as a fundamental right, with focus on Brazilian Federal Constitution of 1988, Federal Law No. 9.394 (Law on guidelines and bases of national education) and Federal Law No. 7.210/1984 (Criminal Enforcement Law), and finally, the official statistics of the National Council of Justice concerning the penitentiary system. The paper also discuss the availability of public education policies in the prison context respecting human rights, while seeking to develop a set of competencies and prepare the individual for social (re)insertion, in the role of citizen aware of his rights and duties.
\end{abstract}

Keywords: Prison system. Education. Rio Grande do Norte.

\footnotetext{
${ }^{1}$ Mestranda do Programa de Pós-Graduação em Planejamento e Dinâmicas Territoriais no Semiárido (Plandites) da Universidade do Estado do Rio Grande do Norte (UERN). gomespessoa@hotmail.com

2 Doutor em Educação. Professor do Programa de Pós-Graduação em Planejamento e Dinâmicas Territoriais no Semiárido (Plandites) da Universidade do Estado do Rio Grande do Norte (UERN). santosjunioralcides@gmail.com
} 


\section{Introdução}

O artigo 206 da Constituição Federal dispõe que "a educação, direito de todas as pessoas e dever do Estado e da família, será promovida e incentivada com a colaboração da sociedade, visando ao pleno desenvolvimento da pessoa, seu preparo para o exercício da cidadania e sua qualificação para o trabalho". Esta garantia incube ao Estado o dever de igualar a todas as pessoas as oportunidades de acessar, permanecer em qualquer nível de educação e, ao mesmo tempo, usufruir de um ensino de alta qualidade. Conforme disposto nos artigos 11 e 17 da Lei de Execução Penal (LEP), é um direito da pessoa privada de liberdade o acesso à assistência educacional, que deve ser oferecido pelo Estado na forma de instrução escolar e formação profissional, visando à reintegração do apenado na sociedade.

Essa lei estabelece ainda que o ensino de 1ำ grau será obrigatório, integrado ao sistema escolar da Unidade Federativa; que o ensino médio, regular ou supletivo, com formação geral ou educação profissional de nível médio, será implantado nos presídios, em obediência ao preceito constitucional de sua universalização. E, por fim, que o ensino profissional será ministrado em nível de iniciação ou de aperfeiçoamento técnico. Destaca-se que o ensino fundamental é apontado na Lei de Execução Penal como nível educacional que deve ser oferecido de forma obrigatória no sistema prisional, sendo que condiciona a oferta dos demais níveis à demanda da população e à disponibilidade de recursos humanos e infraestrutura.

Entretanto, dados do Ministério da Justiça demonstram que nem todos os reeducandos têm acesso a algum tipo de política educacional. Conforme evidenciado pelos dados do Infopen ${ }^{3}$, no ano de 2016 , apenas $12 \%$ da população prisional no Brasil estava envolvida em alguma modalidade de atividade educacional entre aquelas de ensino escolar e atividades complementares. Isso ocorre porque a prisão ainda se constitui como um local de marginalização e exclusão social, que nutre como alicerce o encarceramento e a punição, produzindo e reproduzindo um mecanismo de perpetuação da violência. A variedade de problemas observados no sistema carcerário brasileiro traz reflexões sobre o tipo de

\footnotetext{
${ }^{3}$ Dados divulgados pelo Ministério da Justiça através do Levantamento Nacional de Informações Penitenciárias de junho de 2016, p. 53.
} 
"punição" que estamos reproduzindo, que corrompe ao invés de ressocializar (MEIRA, MONTEIRO; 2017).

O encarceramento é tanto causa como consequência da pobreza; porém, isso não significa que as pessoas pobres sejam mais perigosas que as outras. Em geral, a exclusão é global: exclusão da escola, do mercado de trabalho, da integração social, da convivência familiar, com ausência de relacionamentos (MAEYER, 2006). Partindo dessa realidade, nesse contexto de privação de liberdade e outros direitos, a escola atuante deve preocupar-se não somente com o processo de ensino-aprendizagem, mas também em exercer influência positiva sobre os apenados, a fim de transformar sua realidade.

Não se pretende neste trabalho afirmar que a educação, por si só, garantirá ao sujeito uma forma digna de viver, sem que esteja alinhada com a promoção de políticas eficientes de trabalho, moradia, saúde, dentre outras. De modo contrário, destacamos o seu papel de transformar a realidade dos sujeitos, ao conscientizá-los do seu papel de cidadão, facilitando o exercício de seus direitos e cumprimento de seus deveres.

Para tanto, faz-se necessária a presença de profissionais capazes de promover o processo educacional de forma adequada à realidade do apenado, possibilitando a sua (re)inserção na sociedade após o cumprimento da pena. Sendo assim, a ideia de que a educação no contexto prisional é um privilégio é ultrapassada e não merece prosperar. Conforme disposto no nosso ordenamento legal, o único direito a ser privado com o encarceramento do condenado é o da liberdade, subsistindo todos os seus demais direitos nas esferas individual e coletiva.

O exercício do direito à educação deve observar as seguintes condições: não pode ser considerado como sinônimo de formação profissional, tampouco usado como instrumento de reabilitação social, posto que é uma ferramenta democrática de progresso, não mercadoria. Portanto, a educação deve ser aberta, multidisciplinar e contribuir para o desenvolvimento da comunidade. Não deve ser usada como ferramenta para lidar com conflitos dentro da prisão, e esse direito não deve ser aplicado e tolerado apenas para os apenados de boa conduta (MAEYER, 2006).

Muitas vezes, ao disponibilizar programas voltados à educação técnico-profissional, as quais permitem ao detento aprimorar habilidades para o mercado de trabalho, o Estado 
permite, em determinados estabelecimentos prisionais, unidades de produção de empresas privadas, as quais empregam detentos aproveitando-se dos benefícios fiscais e direitos trabalhistas reduzidos. Para exemplificar, citamos a disposição contida no artigo 29 da Lei de Execução Penal, que permite o pagamento de remuneração abaixo do valor do mínimo legal, estabelecendo como patamar mínimo $3 / 4$ do salário mínimo para uma jornada de trabalho em tempo integral.

Ainda que a prisão não seja o ambiente adequado para promover políticas públicas educacionais, por falta de ferramentas e circunstâncias adequadas, trata-se de um dos lugares onde essas intervenções positivas são mais necessárias para transformação da sua realidade.

Este estudo trata-se de uma pesquisa qualitativa, por ser um processo investigativo com o objetivo de compreender e identificar de modo geral as políticas públicas de educação desenvolvidas em favor dos apenados no Estado do Rio Grande do Norte. Quanto aos seus objetivos e finalidade, o presente estudo funda-se em uma pesquisa de caráter exploratório e descritivo. O estudo exploratório é aquele realizado quando se tem pouco conhecimento acumulado e sistematizado, e, portanto, não existem trabalhos produzidos onde se possam encontrar informações sobre a questão ou o problema (COLLIS; HUSSEY, 2005).

A captura de dados foi realizada por meio de revisão bibliográfica da literatura científica, especialmente artigos científicos, além de documentos e resoluções do Ministério da Educação e da Secretaria Estadual de Educação e Cultura do RN que abordam as políticas públicas de educação desenvolvidas em prol dos condenados à pena privativa de liberdade no RN. Foi analisada também a legislação vigente, que garante a educação como direito fundamental, com enfoque na Constituição Federal Brasileira de 1988, Lei Federal no 9.394, (Lei de Diretrizes e Bases da Educação Nacional) e Lei Federal no 7.210/1984 (Lei de Execução Penal), e, por fim, as estatísticas oficiais do Conselho Nacional de Justiça atinentes ao Sistema Penitenciário. 


\section{Resultados e discussão}

Segundo o Relatório do Levantamento Nacional de Informações Penitenciárias (Infopen), a população prisional no nosso país, em junho de 2016, era de 726.712 pessoas ${ }^{4}$, sendo que o número de vagas no nosso sistema carcerário é de apenas 368.049, acumulando, assim, um déficit de 358.663 vagas em nível nacional. Esse número cresce de forma alarmante, conforme podemos observar no gráfico 1.

\section{Gráfico 1 - Evolução das pessoas privadas de liberdade entre 1990 e 2016}

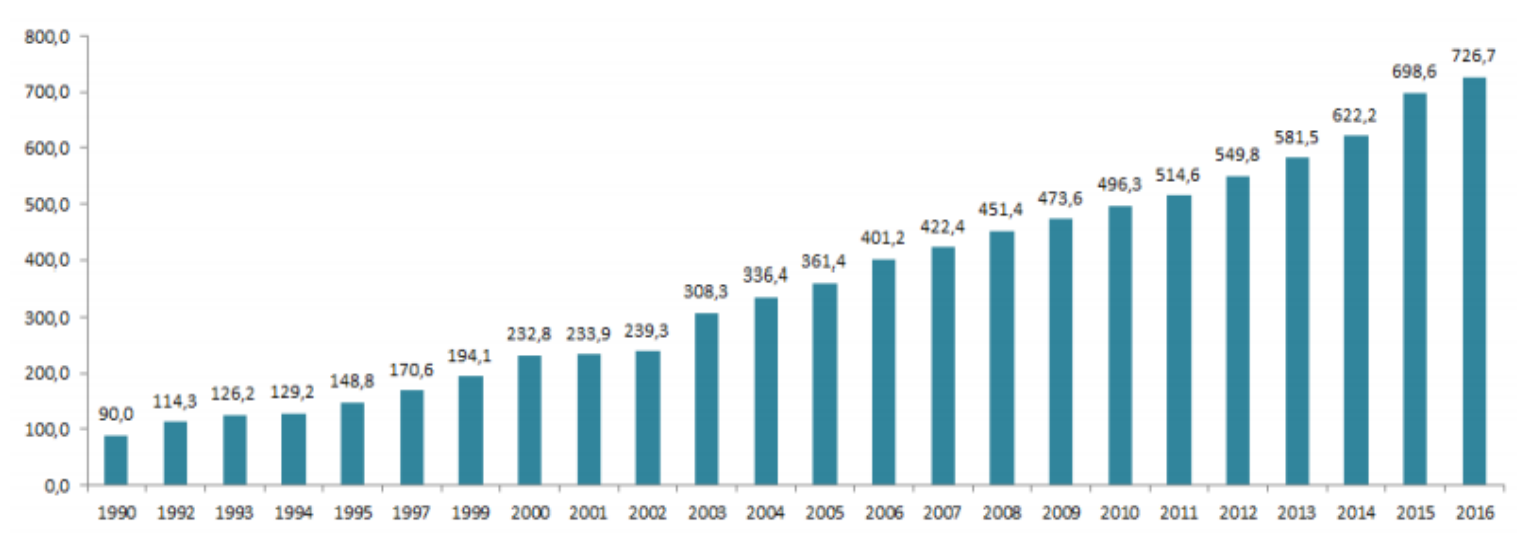

Fonte: Ministério da Justiça. A partir de 2005. Dados do Infopen.

O Infopen, comparando dados fornecidos pelo Ministério da Justiça, chega à conclusão de que, entre os anos de 2000 e 2016, a taxa de aprisionamento aumentou 157\% no Brasil, posto que, em 2000, existiam 137 pessoas presas para cada grupo de 100 mil habitantes, enquanto que, em junho de 2016, eram 352,6 pessoas presas para cada 100 mil habitantes. De acordo com os dados deste mesmo relatório, o Estado do Rio Grande do Norte detinha, no mesmo período, 8.809 encarcerados, enquanto o número de vagas no sistema prisional é de apenas 4.265 , gerando uma taxa de ocupação ${ }^{5}$ de $206,5 \%$ para o referido período. Desses aprisionados, 7.920 são do sexo masculino, e somente 776 são do sexo feminino. Destaca-se

\footnotetext{
${ }^{4}$ Segundo o relatório, para o cálculo da população prisional, foram desconsideradas as pessoas em prisão albergue domiciliar, por não se encontrarem em estabelecimentos penais diretamente administrados pelo Poder Executivo e, também, as centrais de monitoração eletrônica.

${ }^{5} \mathrm{~A}$ taxa de ocupação é calculada pela razão entre o número total de pessoas privadas de liberdade e a quantidade de vagas existentes no sistema prisional.
} 
ainda o fato de $33,7 \%$ dos aprisionados ainda não terem sido condenados, e $40 \%$ dos apenados estarem sentenciados em regime inicial fechado.

O perfil socioeconômico dos detentos do estado mostra que 59\% têm entre 18 e 29 anos, $72 \%$ são da raça negra, $13 \%$ são analfabetos e $50 \%$ têm até o ensino fundamental incompleto, contrastando com o valor abaixo de $1 \%$ referente àqueles com ensino superior completo.

Em contraste com esse cenário apresentado, a Lei no 9.394/1996, conhecida como Lei de Diretrizes e Bases, estabelece a educação como dever da família e do Estado. Foi inspirada nos princípios de liberdade e nos ideais de solidariedade humana, tendo por finalidade o pleno desenvolvimento do educando, bem como o seu preparo para o exercício da cidadania e sua qualificação para o trabalho.

O referido dispositivo legal dispõe ainda que o ensino será ministrado com base nos seguintes princípios: igualdade de condições para o acesso e permanência na escola; liberdade de aprender, ensinar, pesquisar e divulgar a cultura, o pensamento, a arte e o saber; pluralismo de ideias e de concepções pedagógicas; respeito à liberdade e apreço à tolerância; coexistência de instituições públicas e privadas de ensino; gratuidade do ensino público em estabelecimentos oficiais; valorização do profissional da educação escolar; gestão democrática do ensino público, na forma desta Lei e da legislação dos sistemas de ensino; garantia de padrão de qualidade; valorização da experiência extraescolar; vinculação entre a educação escolar, o trabalho e as práticas sociais; consideração com a diversidade étnicoracial; garantia do direito à educação e à aprendizagem ao longo da vida.

Infelizmente, esta legislação não trouxe uma abordagem específica sobre a educação no sistema penitenciário. Contudo, o Plano Nacional de Educação, instituído pela Lei no 10.172/2001, preencheu esta lacuna, ao dispor no rol de seus objetivos e metas da educação de jovens e adultos, implantar, em todas as unidades prisionais, programas de educação de jovens e adultos de nível fundamental e médio, assim como de formação profissional, contemplando para a população carcerária as metas relativas ao fornecimento de material didático-pedagógico pelo Ministério da Educação (MEC) e à oferta de programas de educação a distância. Da mesma forma, a Secretaria de Educação Continuada, Alfabetização e Diversidade e Inclusão do Ministério da Educação (SECADI/MEC), definiu entre seus objetivos 
o apoio à execução de projetos voltados para os apenados, desenvolvidos pelas secretarias estaduais de educação ou por organizações não-governamentais (PLANO..., 2015).

Contudo, não há um instrumento normativo de caráter vinculante que regulamente a oferta de educação formal, informal e profissionalizante durante o cumprimento de pena privativa de liberdade. Essa omissão legislativa contribui para que um número mínimo de pessoas tenha acesso a esse tipo de experiência, para a existência de experiências diversas em cada local de oferta, condicionando o exercício de um direito constitucionalmente garantido à discricionariedade dos agentes políticos e dificultando a continuidade dos estudos em casos de transferência, progressão de regime e término da pena.

Nas diversas regiões - e até dentro de um mesmo estado, como é o caso do Rio Grande do Norte - existem as mais variadas experiências, realizadas de forma isolada, muitas vezes, de forma contrária à estipulada pelas Diretrizes Nacionais da Educação. Para amenizar esta situação, sugere-se a criação da Lei de Diretrizes e Bases Para a Educação de Jovens e Adultos no Sistema Prisional.

O que se observa na prática é que a educação, na prisão, fundamenta-se em justificativas e preocupações: garantir um mínimo de ocupação para os internos (para que a segurança e a calma estejam garantidas), oferecer mão de obra de baixo custo para o mercado de trabalho, amenizar defeitos de personalidade e construir um novo homem, ou uma nova mulher, apresentando atitudes e comportamentos tipicamente religiosos; oferecer ferramentas para a vida externa, reeducar, reduzir a reincidência, etc. Cada uma dessas justificativas é motivada pela visão ideológica das autoridades de cada país (MAEYER, 2006).

O planejamento dessas políticas públicas de educação prisional reflete a opinião pública da sociedade, uma vez que num Estado onde o orçamento para a educação regular é insuficiente, é difícil explicar à população a importância de aplicar parte significativa desse orçamento público na educação prisional, que é vista por muitos segmentos da sociedade - e até mesmo pelos agentes ligados à gestão do sistema penitenciário - como privilégio dos reeducandos.

Visando fomentar o interesse dos apenados na participação de programas educacionais, a remição da pena por estudo foi uma garantia instituída pelo artigo 126 da Lei de Execução Penal, no patamar de redução de um dia de pena a cada 12 horas de frequência 
escolar - atividade de ensino fundamental, médio, inclusive profissionalizante, ou superior, ou ainda de requalificação profissional - divididas, no mínimo, em três dias. Trata-se de uma forma de incentivar a matrícula e a frequência do apenado em instituições de ensino durante o cumprimento de pena. A praxe forense determina que a frequência de cada apenado seja contabilizada e enviada à Vara de Execuções Penais, ao fim de cada semestre ou ano letivo, para que sejam realizados os cálculos e determinada a remição pelo juízo competente.

O Estado do Rio Grande do Norte, através da Secretaria de Estado da Educação e da Cultura - SEEC, dispõe de políticas públicas educacionais para os apenados há mais de duas décadas, com atuação em algumas unidades prisionais espalhadas na capital e no interior do Estado. Entretanto, a oferta desta política pública ainda não consegue atender de forma integral à demanda do estado.

As primeiras experiências se deram por iniciativa da própria instituição prisional ou de membros da sociedade que desenvolviam atividades filantrópicas, de cunho assistencialista. Esses atores sociais buscavam junto à Secretaria de Educação do Estado, especialmente na Subcoordenadoria de Educação de Jovens e Adultos, alternativas para viabilizar a participação dos privados de liberdade em exame. Há também registros de parcerias entre as unidades prisionais e organizações não governamentais - ONG's, Igrejas e voluntários, que desenvolviam, em sua maioria, projetos pontuais de alfabetização para jovens e adultos (PLANO..., 2015).

Inicialmente, a presença da Secretaria de Educação na oferta de educação aos privados de liberdade se dá somente nas duas penitenciárias maiores - Penitenciária Dr. Mário Negócio - situada em Mossoró - e na Estadual de Alcaçuz - localizada em Nísia Floresta. Contudo, a partir do ano de 2006, por iniciativa da Ouvidoria do Cidadão e do Sistema Penitenciário/SEJUC, em contato com a Coordenação do Programa Brasil Alfabetizado, foram implantadas turmas de alfabetização em algumas unidades prisionais. Entretanto, não há uma continuidade no processo de aprendizagem dos educandos ao concluírem essa etapa inicial de estudo, por motivos que vão desde a saída do apenado do sistema prisional à falta de um diagnóstico sistemático para atender à demanda de forma qualificada (PLANO..., 2015).

No que pese haver a oferta regular dos ensinos fundamental e médio na modalidade EJA nas maiores penitenciárias do Estado, conforme as demandas que se apresentam, esses 
estudantes não eram inseridos nos dados do Censo Escolar. Nessas penitenciárias, há participação dos educandos nos Exames, por meio da Comissão Permanente de Educação de Jovens e Adultos, sob a jurisdição das Diretorias Regionais de Ensino - DIRED. Entretanto, constata-se a predominância de turmas de alfabetização do Programa Brasil Alfabetizado RN Alfabetizado, pelo fato de ser mais simples o processo de implantação de turmas, dado ao déficit de professores vinculados ao estado (PLANO..., 2015).

Por ocasião do Plano de Plano Estadual de Educação nas Prisões, de 2015, foi traçado o perfil educacional dos 7.044 apenados que, à época, estavam em estabelecimentos prisionais. Os dados foram sumarizados no quadro 1.

\section{Quadro 1 - Perfil Educacional dos Presos}

\begin{tabular}{lrr}
\hline \multicolumn{1}{c}{ NÍVEL } & QUANTIDADE & PERCENTUAL \\
\hline Alfabetizados & 1.291 & $18,3 \%$ \\
Não alfabetizados & 568 & $8,1 \%$ \\
Ensino Fundamental incompleto & 3.852 & $54,7 \%$ \\
Ensino Fundamental (anos iniciais)* & - & - \\
Ensino Fundamental (anos finais)* & - & - \\
Ensino Fundamental completo & 323 & $4,6 \%$ \\
Ensino Médio incompleto & 420 & $6,0 \%$ \\
Ensino Médio completo & 344 & $4,9 \%$ \\
Ensino Superior incompleto & 40 & $0,6 \%$ \\
Ensino Superior completo & 16 & $0,2 \%$ \\
Pós-Graduação & 1 & $0,01 \%$ \\
Não informado & 189 & $2,7 \%$ \\
\hline Total & 7.044 & $100,0 \%$ \\
\hline
\end{tabular}

Fonte: Plano de Plano Estadual de Educação nas Prisões de 2015 - Elaborado com dados da Secretaria de Estado da Educação e da Cultura do RN.

Em contraponto, no mesmo ano, só foram disponibilizadas 196 vagas para os interessados em cursar os anos iniciais do ensino fundamental, 128 para o ensino fundamental (anos finais), 54 vagas para turmas de ensino médio e 0 vagas para alfabetização e ensino superior. Analisando estes números, não restam dúvidas de que a oferta é insuficiente para cobrir a demanda de modo satisfatório.

A educação para os apenados do Rio Grande do Norte é possibilitada por verbas destinadas pelo Governo Federal, custeando as despesas na forma disposta pela 
Resolução/CD/FNDE no 48, de 2 de outubro de 2012, com professores contratados temporariamente, com currículos selecionados através de edital.

Os apenados devem ser obrigatoriamente matriculados em Centros de Educação de Jovens e Adultos, ou, na sua ausência, em escolas da rede estadual, denominadas Escolas Certificadoras, cujas salas de aula funcionam dentro das próprias unidades prisionais. Mister destacar que o desempenho dos professores deve ser acompanhado pela equipe pedagógica da escola certificadora; entretanto, o monitoramento do programa fica a cargo das Diretorias Regionais de Educação e Subcoordenadoria de Educação de Jovens e Adultos.

Como no Estado não existem escolas específicas para atendimento exclusivo de reeducandos, estes são matriculados em escolas vinculadas à rede estadual de ensino, servindo as "celas de aula" como anexos da escola. Contudo, são disponibilizados todos os procedimentos necessários ao seu funcionamento, tais como matrículas, inclusão de dados no Censo Escolar e distribuição de material didático.

No que se refere à estrutura, em todo o estado somente a Penitenciária Federal em Mossoró, a CDP de Apodi, a Penitenciária Estadual de Parnamirim, o Complexo Penal Estadual Agrícola Mário Negócio e o Complexo Penal João Chaves possuem biblioteca acessível aos apenados. Ressaltamos que, na maioria dos casos, a sua implantação é recente, tendo ocorrido nos três últimos anos.

A distribuição de merenda escolar é uma questão polêmica nesse tipo de estabelecimento, em razão de alegações como falta de condições para transporte e armazenamento tanto por parte da entidade escolar como da unidade prisional. Em algumas unidades, os alunos são beneficiados quando os professores se encarregam de fazer por conta própria este transporte no momento em que se deslocam para ministrar as aulas.

A educação básica, ofertada na modalidade Educação de Jovens e Adultos no RN, está dividida em nove períodos relativos ao ensino fundamental e outros três períodos referentes ao ensino médio. Cada período tem duração de um semestre, com carga horária de 400 horasaula, ministrados em 100 dias letivos, equivalentes a um ano escolar, tal como a ofertada em escolas que atuam com o EJA convencional.

A obtenção de certificado de conclusão do ensino fundamental e médio também é possível mediante a relação de exames, através da Comissão Permanente de Exames de 
Educação de Jovens e Adultos, pela eliminação dos componentes curriculares, de acordo com o tempo de estudante, já que a oferta era permitida a partir do 20 segmento-ensino fundamental e do ensino médio (PLANO..., 2015).

Há também a disponibilidade de participação de detentos no Exame Nacional do Ensino Médio - ENEM, mas o processo se dá de forma diferenciada para as pessoas privadas de liberdade. As inscrições dos interessados, muitas vezes, são realizadas pelos responsáveis pedagógicos das escolas certificadoras, que também se encarregam de acessar o resultado dos exames, repassá-los aos detentos e inscrevê-los em programas de acesso ao ensino superior, quando for o caso.

Para o docente, realizar o seu trabalho no contexto prisional não deve ser um martírio ou uma punição imposta pelos órgãos administrativos aos quais se encontra vinculado; no entanto, é necessário que tenha à sua disposição infraestrutura e recursos adequados para exercer seu ofício.

Em sua maioria, as escolas certificadoras possuem um projeto político pedagógico, contudo, raramente se observa a presença de disposições específicas sobre a educação prisional e suas especificidades. Esta situação dificulta a execução e o planejamento de atividades adequadas à realidade do encarcerado.

Entre 2010 e 2011, sob a justificativa de déficit no número de profissionais da educação no estado, o que impossibilitaria a designação de docentes para atuar no sistema prisional, foram contratados por edital universitários para exercer tais funções a título de estágio, de forma a garantir o funcionamento das novas turmas implantadas em algumas unidades prisionais. Esses estagiários deveriam preencher alguns requisitos básicos, como estar com 50\% da carga horária do seu curso de licenciatura ou pedagogia, possuir experiência em sala de aula, afinidade com temáticas relativas a direitos humanos, sobretudo haver atuado na EJA. No entanto, nem todos esses requisitos eram atingidos, dada a dificuldade em conseguir candidatos para atuarem no sistema penitenciário (PLANO..., 2015).

Não há, na nossa legislação, qualquer previsão de incentivo ou gratificação para o profissional do magistério estadual que atue no sistema prisional, o que pode ser apontado como uma das causas para o desinteresse dos profissionais atuarem nessa área. 
De acordo com o Plano Estadual de Educação nas Prisões de 2015, a oferta de educação a pessoas privadas de liberdade, no $\mathrm{RN}$, deve se basear na garantia do direito à educação, nos princípios da educação em direitos humanos e na articulação entre a educação escolar, na modalidade Educação de Jovens e Adultos, e educação profissional e educação a distância. Dessa forma, almeja-se desenvolver um currículo flexível em sua organização, no qual sejam respeitadas as particularidades de pessoas que cumprem pena em estabelecimentos prisionais, sua cultura, seus interesses e necessidades formativas. Também devem ser adequados tempo e espaço, de modo a permitir percursos individualizados. Atividades e vivências socializadoras deverão privilegiar aspectos culturais, esportivos e recreativos orientados, de modo a enriquecer as experiências geradas pelo convívio salutar da diversidade presente nesses espaços.

No que pese esse esforço do estado e as disposições da legislação vigente, ainda encontramos uma grande lacuna entre a garantia do direito e o efetivo acesso e qualidade do ensino. Esse quadro fático é evidenciado pela inexistência de turmas de ensino na totalidade das unidades prisionais, bem como na ausência de uma política pública efetiva para o acompanhamento escolar do apenado, após o término do cumprimento da pena, garantindo a permanência e a continuação da sua formação.

\section{Considerações finais}

A discussão do tema ressocialização, sob a ótica dos direitos humanos, tem como objetivo debater a necessidade de reforma na política prisional, bem como o grau de efetividade das suas políticas públicas na (re)inserção social do indivíduo. De maneira alguma se pretende negar o caráter punitivo da pena, mas, de modo contrário, demonstrar que, sendo praticamente certo que os apenados voltarão ao convívio social, o melhor caminho é aproveitar o período de encarceramento para promover políticas públicas que possibilitem a melhor integração destes indivíduos na sociedade.

Portanto, conclui-se que a privação da liberdade por meio do encarceramento por si só não viabiliza a ressocialização. O cumprimento de pena privativa de liberdade, em estabelecimentos prisionais com foco na restrição de direitos e garantias, sem a preparação 
do reeducando para o mercado de trabalho ou a garantia de estudo para facilitar sua inserção na sociedade, são práticas perversas, incompatíveis com o grau de desenvolvimento atingido no século XXI.

Somente uma reforma no sistema prisional do Rio Grande do Norte, com foco na educação formal, informal e profissional, aliada à promoção de políticas públicas inclusivas no período pós-cumprimento, seria capaz de garantir o caráter ressocializador da pena. Analisando as estatísticas recentes relativas à reincidência criminal fornecidas pelo CNJ, em seu Relatório Especial de Jurisdição de 2015, percebe-se que a necessidade de implementação dessas mudanças é urgente, especialmente no que diz respeito a investimentos em infraestrutura e recursos humanos, bem como à capacitação dos agentes públicos responsáveis pelos detentos, a fim de possibilitar que, ao fim do cumprimento da pena, eles possam retornar ao convívio social de forma digna.

A construção de um processo de ensino que conduza o reeducando à reflexão do seu papel de cidadão no presente e suas expectativas para o futuro é um desafio em razão da sua realidade e das dificuldades do encarceramento. Nesse contexto, faz-se necessário promover um ambiente favorável à alfabetização e incentivar a leitura: as prisões nunca serão um ambiente tão adequado para qualquer tipo de ensino ou aprendizagem quanto uma escola. Mas podem ser transformadas pela instalação de uma biblioteca, pela criação de áreas de leitura, nas quais os livros possam ser trocados, e pela autorização para deixar as luzes das celas acesas por mais tempo para que os internos possam ler (MAEYER, 2006).

Existem exemplos positivos a serem seguidos, como é o caso do estado da Paraíba, no qual o envolvimento da Universidade Estadual da Paraíba (UEPB) na implementação da Política Nacional Criminal e Penitenciária culminou com a instalação do Campus Universitário Avançado "Dom José Maria Pires", ou Campus Avançado do Serrotão, operando diretamente no interior da Penitenciária Regional Raimundo Asfora e da Penitenciária Feminina de Campina Grande, oferecendo educação a um elevado número de detentos daquelas unidades prisionais.

Deve ser uma preocupação a disponibilização de políticas públicas de educação no contexto prisional, respeitando-se os direitos humanos, ao mesmo tempo em que se procura 
desenvolver um conjunto de competências que preparem o indivíduo para a (re)inserção social, no seu papel de cidadão consciente de seus direitos e deveres.

Para tanto, é fundamental o oferecimento de uma educação continuada, que não seja interrompida por fatores como a progressão de regime, a transferência para prisões de uma entidade política ou administrativa diferente ou até mesmo o fim do cumprimento da pena.

Sugerimos também investir na qualificação de profissionais da rede estadual de ensino para atuarem na educação prisional, em razão da crescente demanda e necessidade de ampliação das políticas públicas. Para tanto, é indispensável oferecer cursos de pós-graduação específicos sobre educação de jovens e adultos com foco na educação prisional. Essa oportunidade possibilitaria que os agentes públicos buscassem a qualificação necessária para o atendimento educacional e profissional prestado aos reeducandos.

\section{Referências}

BRASIL. Constituição da República Federativa do Brasil. Disponível em: http://www.planalto.gov.br/ccivil_03/constituicao/constituicao.htm. Acesso em: 16 de maio 2018.

. Lei no 7.210, de 11 de julho de 1984. Institui a Lei de Execução Penal. Disponível em: http://www.planalto.gov.br/ccivil_03/leis/I7210.htm. Acesso em: 21 de maio 2018.

. Lei no 9.394, de 20 de dezembro de 1996. Estabelece as diretrizes e bases da educação nacional. Disponível em: http://www.planalto.gov.br/ccivil_03/LEIS/I9394.htm. Acesso em: 18 de maio 2018.

. Levantamento Nacional de Informações Penitenciárias: Atualização - Junho de 2016. Ministério da Justiça e Segurança Pública - Departamento Penitenciário Nacional. Brasília, 2017. http://www.justica.gov.br/news/ha-726-712-pessoas-presas-no-brasil/relatorio_ 2016_junho.pdf. Acesso em: 15 de maio 2018.

Ministério da Educação. Resolução no 2, de 19 de maio de 2010. Dispõe sobre as Diretrizes Nacionais para a oferta de educação para jovens e adultos em situação de privação de liberdade nos estabelecimentos penais. Disponível em: http://portal.mec.gov.br/index.php?option=com_docman\&view=download\&alias=5142rceb 002-10\&category_slug=maio-2010-pdf\&Itemid=30192. Acesso em: 15 de maio 2018.

Ministério da Educação. Resolução/CD/FNDE no 48, de 2 de outubro de 2012. Estabelece orientações, critérios e procedimentos para a transferência automática de 
recursos financeiros aos estados, municípios e Distrito Federal para manutenção de novas turmas de Educação de Jovens e Adultos, a partir do exercício 2012. Brasília, 2012.

Disponível em: http://pronacampo.mec.gov.br/images/pdf/resoluca_48_02102012.pdf. Acesso em: 21 de maio 2018.

CNJ. Reunião especial de jurisdição. 2017. Disponível em:

http://www.cnj.jus.br/files/conteudo/arquivo/2017/02/b5718a7e7d6f2edee274f93861747 304.pdf. Acesso em: 18 de set. 2017.

GOVERNO DO ESTADO DO AMAZONAS. Plano Estadual de Educação nas Prisões. Governo do Estado do Rio Grande do Norte. Natal, 2015. Disponível em: http://depen.gov.br/DEPEN/dirpp/cgpc/acoes-de-educacao/planoprisional2016_nadja_ 2vers ofinalrn.pdf. Acesso em: 16 de maio 2018.

GRACIANO, Mariângela. Educação também é direito humano. 2005. São Paulo: Ação Educativa, Plataforma Interamericana de Direitos Humanos, Democracia e Desenvolvimento - PIDHDD. Disponível em:

http://www.dhnet.org.br/dados/livros/edh/a_pdf/livro_acao_educativa_direito_educacao. pdf. Acesso em: 15 de maio 2018.'

MAEYER, Marc de. Na prisão existe perspectiva da educação ao longo da vida? Alfabetização e cidadania. Revista Brasileira de Educação de Jovens e Adultos, Brasília: RAAAB, UNESCO, Governo Japonês, n. 19, p. 17-37, jul. 2006. Disponível em: http://unesdoc.unesco.org/images/0014/001465/146580por.pdf. Acesso em: 15 de maio 2018.

MEIRA, Claudia de Jesus; MONTEIRO, Rayanne. Educar em prisões: um caminho para ressocialização de jovens e adultos. Recife, 2017. Disponível em: http://www.prisoes2017.sinteseeventos.com.br/simposio/view?ID_SIMPOSIO=22. Acesso em: 22 de maio 2018.

SAUER, Adeum Hilário. Diretrizes Nacionais para a oferta de educação para jovens e adultos em situação de privação de liberdade nos estabelecimentos penais. Conselho Nacional de Educação - Ministério da Educação. Disponível em: http://portal.mec.gov.br/index.php?option=com_docman\&view=download\&alias=4445pceb 004-10\&Itemid=30192. Acesso em: 6 de maio 2018. 